\title{
Efeito de resíduos de gesso e de granito em produtos da indústria de cerâmica vermelha: revisão bibliográfica
}

\section{Effect of gypsum and granite residues on products from the red ceramic industry: Literature review}

\footnotetext{
${ }^{1}$ Instituto Federal do Piauí - Campus Floriano, CEP: 64800-000, Floriano, PI, Brasil.

${ }^{2}$ Instituto Federal do Piauí - Campus Teresina Central, CEP: 64000-040, Teresina, PI, Brasil.

${ }^{3}$ Universidade Federal do Piauí, CEP: 64049-550, Teresina, PI, Brasil.

e-mail: eng.kelson@ifpi.edu.br, robertoarruda@ifpi.edu.br, jmematos@ufpi.edu.br
}

\begin{abstract}
RESUMO
A indústria da cerâmica vermelha compreende materiais empregados na construção civil (tijolos, telhas, argila expandida, entre outros) e tem grande importância para o desenvolvimento econômico brasileiro, assim tem crescido a procura por seus produtos, causando um problema de escassez de reservas de matérias-primas de boa qualidade e em locais economicamente adequados. Outros materiais também utilizados na construção civil, como o granito (principal produto da indústria de rochas ornamentais) e gesso de revestimento tem apresentado crescimento em sua demanda, gerando, em seu processo de beneficiamento, grande quantidade de resíduos, provocando impacto negativo ao meio ambiente. A reciclagem de resíduos está cada vez mais em evidência em razão do grande volume gerado pelo setor. A indústria de cerâmica vermelha, por sua característica heterogênea, tem se destacado na incorporação de resíduos, tanto por apresentar vantagens, quanto pelo maior rigor das leis atuais. Assim, este trabalho tem por finalidade expor uma visão geral sobre os efeitos da utilização dos resíduos industriais, gesso e granito, em indústria de cerâmica vermelha, apresentando também resultados de trabalhos executados nesta área. Os resultados apontam quantidade escassa de pesquisas na área de reciclagem de resíduos de gesso e granito, e que a utilização dos mesmos em massa cerâmica está em conformidade com a legislação vigente e ainda contribui para a redução dos impactos negativos causados ao meio ambiente devido ao seu descarte em locais indevidos.
\end{abstract}

Palavras-chave: Cerâmica Vermelha, Gesso, Granito, Resíduo, Reciclagem.

\section{ABSTRACT}

The red ceramics industry comprises materials used in construction (bricks, tiles, expanded clay, among others) and is of great importance for Brazilian economic development, so the demand for its products has grown, causing a problem of scarcity of reserves of good quality raw materials and in economically appropriate places. Other materials also used in construction, such as granite (main product of the ornamental stone industry) and gypsum coating have shown growth in their demand, generating large amounts of waste, causing negative impact on the environment. The recycling of waste is increasingly evident due to the large volume generated by the sector. The red ceramic industry, due to its heterogeneous character, has been prominent in the incorporation of waste, as much to present advantages as the greater rigor of the current laws. The purpose of this work is to present an overview of the effects of the use of industrial waste, gypsum and granite, in the red ceramic industry, and also presents results of work carried out in this area. The results point to a scarce amount of research in the area of waste recycling of gypsum and granite, and that their use in ceramic mass complies with current legislation and also contributes to the reduction of negative impacts caused to the environment due to its disposal in undue places. 
Keywords: Red Ceramics, Gypsum, Granite, Residue, Recycle.

\section{INTRODUÇÃO}

O setor da construção civil, em particular na manufaturação de insumos, está em constante crescimento, a mesma, embora seja responsável por relevante demanda ambiental, também apresenta grande impacto positivo na sociedade e na economia. No Brasil, este setor representa atualmente 5\% do PIB nacional e há indícios de crescimento. Os produtos cerâmicos estão entre os mais utilizados na construção civil e assim é uma atividade de base ao possibilitar à construção civil, em geral, desde a mais simples à mais sofisticada [1].

$\mathrm{O}$ aumento da necessidade de argila (principal matéria-prima) por parte da indústria cerâmica tem provocado impactos ao meio ambiente, tais como o aumento do volume de matéria-prima das jazidas e diminuição de sua vida útil, possibilidade de alteração de paisagem e destruição de natureza da região da jazida, entre outros. Assim, é essencial que haja maneiras de diminuir o impacto ambiental, como por exemplo, a incorporação de resíduos em substituição parcial da argila [2].

O ramo da construção civil tem impulsionado também uma demanda pela extração de rochas ornamentais, em especial o granito e de outros materiais como o gesso utilizado em revestimento de paredes e forros de residências. No Brasil, a produção de rochas ornamentais está posicionada num nível bastante elevado, chegando a 9,3 milhões de toneladas no ano de 2013; sendo que deste total 4,6 milhões de toneladas são apenas de granito [3]. Já a produção de gesso no Brasil é estimada em 5,1 milhões de toneladas sendo $37 \%$ para a indústria cimenteira, $52 \%$ para a construção civil, $9 \%$ para a indústria agrícola e $2 \%$ para outros fins. Além disso, vale destacar que vem aumentando a demanda de gesso com o desenvolvimento do ramo da construção civil [4].

Todo processo produtivo industrial, como o beneficiamento de gesso e granito, é caracterizado pela utilização de insumos que, submetidos a uma transformação, dão lugar a produtos e com eles, os resíduos. No beneficiamento do granito, estima-se uma perda de 20 a $25 \%$ do volume dos blocos, em que o principal resíduo gerado é de baixa granulometria, que, normalmente, é descartado pela indústria. As principais fontes de resíduos de gesso na construção civil são as atividades de revestimento (88\%), as chapas de gesso acartonado (8\%) e os componentes pré-moldados (4\%), gerando, apenas na construção civil, um montante total de resíduos de gesso de 1,316 milhões de toneladas [4].

A disposição final destes resíduos (gesso e granito) tem acarretado sérios problemas ambientais já que muitas vezes não há tratamento adequado, ocorrendo contaminação do solo e subsolo e assoreamento de córregos e rios. Assim, atualmente buscam-se maneiras de reciclar esses resíduos a fim de diminuir os impactos na natureza.

Atualmente as indústrias têm buscado formas de minimizar os resíduos gerados, assim como encontrar meios de reutilizar os mesmos de maneira adequada, principalmente devido às novas leis ambientais em vigor. A incorporação em produtos cerâmicos é uma forma de tratamento para os resíduos industriais, reduzindo o volume de matéria-prima e imobilizando os mesmos a fim de evitar o impacto negativo ao meio ambiente. A indústria de cerâmica vermelha tem apresentado interesse em desenvolver materiais novos com a incorporação de resíduos, podendo apresentar propriedades tecnológicas melhores e assim buscar o desenvolvimento de novas tecnologias viáveis para a reutilização desses resíduos [5].

Assim, ressalta-se a importância do estudo realizado tendo em vista a necessidade de reciclagem de resíduos de gesso e granito e a possibilidade de utilização dos mesmos na indústria de cerâmica vermelha, contribuindo-se assim para a reciclagem e qualidade ambiental, desenvolvimento de novos materiais e a sustentabilidade do setor cerâmico. O estudo tem por objetivo principal analisar os efeitos da utilização de resíduos de gesso e granito em produtos da indústria de cerâmica vermelha, buscando pesquisas já realizadas na área.

\section{A CERÂMICA E SEU PERFIL DE INDÚSTRIA}

A cerâmica, que é praticamente tão antiga quanto à descoberta do fogo, mesmo utilizando os antigos métodos artesanais, pode produzir artigos de excelente qualidade. Nos últimos anos, acompanhando a evolução industrial, a indústria cerâmica adotou a produção em massa, garantida pela indústria de equipamentos, e a introdução de técnicas de gestão, incluindo o controle de matérias-primas, dos processos e dos produtos fabricados [6].

Atualmente, o termo cerâmica se refere a todo material inorgânico não metálico obtido após tratamento térmico a altas temperaturas, por exemplo: pisos, louças para banheiro, vidros, fibras óticas, utensílios culinários, combustível nuclear, implantes ósseos e dentários, entre outros. Esta classe de materiais apresenta 
propriedades específicas como alta estabilidade química, resistência à corrosão e ao calor, entre outras.

A Indústria Cerâmica no Brasil e no Mundo, atualmente, pode ser divida em vários setores que apresentam algumas características diferentes e níveis de tecnologia distintos: cerâmica vermelha, cerâmica branca, materiais refratários, cerâmica avançada, revestimentos cerâmicos [7].

A cerâmica estrutural ou vermelha, foco deste trabalho, é caracterizada pela coloração avermelhada de seus produtos e que são utilizados na construção civil, tais como tijolos, blocos, telhas, tubos, lajes para forro, elementos vazados, agregados leve de argila expandida e outros. São produtos que oferecem boa durabilidade, conforto térmico e acústico, baixo custo, entre todos os envolvidos na cadeia produtiva da construção civil [8].

A produção cerâmica é realizada, em sua maioria, por empresas de pequeno e médio porte, de capital nacional, o que aposta ainda um baixo investimento neste ramo da construção civil. As jazidas de argila, que produzem matérias-primas com qualidade e regularidade, constituem-se em unidades mineradoras e fornecedoras à indústria de Cerâmica Vermelha ou também com unidade própria de extração [9].

O Brasil apresenta grande potencial mineral em relação à argila, embora a extensão destas jazidas ainda seja, geralmente, mal dimensionada ou pouco conhecida. As principais bacias sedimentares brasileiras, portadoras de depósitos de argila para uso em cerâmica vermelha estão distribuídas por todo o Brasil e destacam-se: Amazonas, Parnaíba, Paraná, Potiguar, Recôncavo, São Francisco, entre outras. As regiões sul e sudeste se destacam com as maiores polos cerâmicos do Brasil localizados próximos às principais jazidas do país, com destaque para os estados de São Paulo, Minas Gerais, Paraná e Santa Catarina [10].

A localização das indústrias cerâmicas é determinada por dois fatores principais: a proximidade de jazidas (em função do volume de matéria-prima processada e da necessidade de transporte de grande volume e peso) e a proximidade dos mercados consumidores (tendo em vista os custos de transporte). Quanto maior o grau de qualidade da argila, maior é a importância assumida por esse fator locacional. Uma empresa localizada longe da jazida somente se justifica quando essa é de qualidade excepcional [9].

A indústria de cerâmica vermelha utilizada uma massa monocomponente ou massa simples, que significa que a mesma é composta apenas por uma substância, neste caso a argila. Normalmente é realizada, pelo ceramista, uma mistura entre dois tipos de argila para criação da massa final utilizada confecção dos produtos cerâmicos: uma argila "gorda" que possui granulometria fina e alta plasticidade e uma argila "magra" que possui menos plasticidade e normalmente rica em quartzo. Por ser um produto de baixo valor unitário a massa cerâmica [11].

Levantamentos mostram que a indústria da cerâmica vermelha merece destaque no cenário nacional correspondendo a 7,3\% do Produto Interno Bruto (PIB), formada por aproximadamente 7430 empresas no Brasil, empregando diretamente 293 mil trabalhadores e gerando 1,25 milhões de empregos indiretos, além disso, apresenta um faturamento anual de R $\$ 6$ bilhões, a produção brasileira de blocos/tijolos alcançou 4 bilhões de peças por mês, enquanto o consumo de argila para a produção desses materiais chega a 7,8 milhões de toneladas mensalmente [9].

A mão de obra utilizada na produção de cerâmica no Brasil é em geral pouco qualificada, e com alta rotatividade, outra característica importante é a matriz energética da produção, trata-se de lenha ou resíduos de madeira, o que pode provocar grandes desmatamentos para que a produção aumente cada vez mais.

O setor de cerâmica vermelha tem buscado uma melhor produtividade e sustentabilidade, além de aderir a programas governamentais como o Programa Setorial de Qualidade (PSQ) que tem como objetivo implantar em seu processo produtivo: uma melhor gestão, o licenciamento ambiental, a inovação tecnológica e a eficiência energética, além da busca por tratamento dos resíduos gerados [12].

\section{INDÚSTRIA DE ROCHAS ORNAMENTAIS}

As rochas ornamentais compreendem os materiais geológicos naturais que podem ser extraídos em blocos ou placas, cortados em formas variadas e beneficiados por meio de serragem, polimento, lustro e outros acabamentos de face. Seus principais campos de aplicação abrangem tanto peças isoladas, como esculturas, tampos e pés de mesa, balcões, lápides e arte funerária em geral, quanto edificações, destacando-se, neste caso, os revestimentos internos e externos de paredes, pisos, colunas, pilares, soleiras, telhados, dentre outros [3].

Do ponto de vista comercial, as rochas ornamentais são divididas basicamente em mármores e granitos, caracterizando-se, os primeiros, como rocha carbonática passível de polimento, incluindo os calcários e os mármores propriamente ditos; e os granitos - expressão generalizada para as rochas silicáticas, que recebem polimento - como os granitos propriamente ditos, os sienitos, charnoquitos, basaltos e rochas similares, petrograficamente classificáveis como de origem ígnea [13]. 
Pela estreita interface com o macrossetor da construção civil, que no Brasil responde por quase $20 \%$ do PIB, as rochas ornamentais evidenciam significativa expressão econômica e social, inclusive como vetor de geração de emprego, interiorização do desenvolvimento e captação de divisas. Entre negócios relativos aos mercados interno e externo, incluindo a comercialização de máquinas e insumos, além da prestação de serviços, as transações brasileiras com rochas ornamentais movimentam cerca de US\$ 5 bilhões/ano [3].

O Brasil, em 2014, colocou-se entre os grandes produtores e exportadores mundiais, superando vários países europeus e destacando-se como a principal grife para rochas graníticas. Atualmente, cerca de 10.000 empresas, dentre as quais 400 exportadoras, integram a cadeia produtiva do setor de rochas no Brasil, respondendo por 120 mil empregos diretos e 360 mil indiretos. Assume-se a existência de 1.400 frentes ativas de lavra, responsáveis pela produção de aproximadamente 1.000 variedades comerciais [3].

A Tabela 1 apresenta o setor da indústria de rochas ornamentais no Brasil e a Tabela 2 apresenta os principais tipos de rochas ornamentais produzidas no Brasil, destacando-se o granito, como principal rocha ornamental do Brasil, com quase metade do total produzido.

Tabela 1: Setor de Rochas Ornamentais no Brasil

\begin{tabular}{l|c|c}
\hline \multicolumn{3}{c}{ O Setor de Rochas Ornamentais no Brasil - Situação Atual e Perspectivas para 2020 } \\
\hline & Situação Atual & Perspectivas 2020 \\
\hline Produção & 9,3 milhões t/ano & 13,5 milhões t/ano \\
\hline Exportação & US\$ 1,1 bilhão/ano & US $\$ 2,0$ bilhão/ano \\
\hline Consumo Interno* & 72 milhões $\mathrm{m}^{2} / \mathrm{ano}$ & 100 milhões $\mathrm{m}^{2} / \mathrm{ano}$ \\
\hline Frentes de Lavra & 1.400 & 1.800 \\
\hline Empregos Diretos & 120.000 & 170.000 \\
\hline
\end{tabular}

(*) Inclui rochas de processamento simples e especial. Fonte: ABIROCHAS, 2016.

Tabela 2: Produção da Indústria de Rochas Ornamentais no Brasil

\begin{tabular}{l|l|l}
\hline Tipo de Rocha & $\begin{array}{l}\text { Produção } \\
\text { (Milhão t) }\end{array}$ & $\begin{array}{l}\text { Participação Per- } \\
\text { centual }\end{array}$ \\
\hline Granito e similares & 4,6 & 49,5 \\
\hline Mármore e travertino & 1,7 & 18,2 \\
\hline Ardósia & 0,6 & 6,5 \\
\hline Quartzito foliado & 0,6 & 6,5 \\
\hline Quartzito maciço & 0,6 & 6,5 \\
\hline Pedra Miracema & 0,2 & 2,1 \\
\hline Outros (basalto, pedra Cariri, pedra-sabão, pedra Morisca) & 1,0 & 10,7 \\
\hline Total estimado & 9,3 & 100,0 \\
\hline
\end{tabular}

Fonte: ABIROCHAS, 2016.

O beneficiamento de rochas ornamentais visa basicamente a transformação dos blocos, extraídos na fase de lavra, em produtos finais ou semiacabados. Desta forma, podem se separar as fases de beneficiamento em primário, ou desdobramento, e secundário. O primeiro compreende a preparação e serragem dos blocos em chapas de espessura variável, usualmente dois ou três centímetros. No segundo processo, as chapas são submetidas a acabamento superficial, com ou sem resinagem, que pode ser um simples desbaste, polimento, escovado, flameado ou outros tipos, assim como a produção de ladrilhos e outras peças [14].

De um modo geral, granitos são rochas ígneas, intrusivas e cristalinas, de textura granular, contendo como minerais essenciais feldspato e quartzo. O granito é um material de alta qualidade tradicional extensivamente distribuído por toda a crosta continental da terra [15].

Segundo a Norma Brasileira 6502 (1995), o granito é uma rocha plutônica ou intrusiva granular, onde basicamente é formada por quartzo, feldspato, e consequentemente também, por biotita e moscovita [16].

As utilizações para o granito são praticamente ilimitadas, apresentando uma grande quantidade de combinações de suas qualidades tanto estéticas quanto estruturais (durabilidade, resistência, facilidade de aplicação), como arquitetura em locais como shoppings, escolas, hospitais ou casas, pavimentação de vias para veículos e para pedestres, de praças e parques, na construção de jardins, fontes, bancos ou assentos, além de artigos funerários e decoração como em esculturas ou estátuas e até balcões, bancadas, pias ou objetos decorativos [17]. 


\section{INDÚSTRIA DE GESSO DE REVESTIMENTO}

O gipso é uma rocha sedimentar que apresenta basicamente em sua composição a gipsita. A gipsita é o mineral compacto de baixa dureza, pouco solúvel em água, que é a matéria-prima para o gesso; sua fórmula química é $\mathrm{CaSO}_{4}$. $2 \mathrm{H}_{2} \mathrm{O}[18]$.

A gipsita é um mineral industrial produzido em diversos países do mundo que movimentam cerca de 125 milhões de toneladas por ano. Sendo uma mercadoria de baixo valor unitário, o seu comércio internacional é limitado e a sua importância ressalta na sua transformação a jusante, atrelada principalmente à cadeia da construção civil, em produtos como o cimento e os manufaturados do gesso. Outra cadeia em que ela se insere é na vertente do agronegócio pelas suas características de condicionador e fertilizante de solos [19].

A região nordeste do Brasil, com uma população de 46 milhões de habitantes e um PIB de US\$ 117,5 bilhões, apresenta polos dinâmicos de desenvolvimento e grandes recursos naturais com fantásticas possibilidades de investimento. Integra, entre outras riquezas do solo nordestino, o Polo Gesseiro do Nordeste do Brasil, um dos maiores depósitos exploráveis de gipsita do continente americano, abrangendo vários Estados da Federação, numa área de $24.000 \mathrm{~km}^{2}$ [4].

O Brasil detém reservas significativas de gipsita localizadas todas elas nas regiões norte, nordeste e centro oeste do país, posicionando-se como o $16^{\circ}$ produtor mundial, suprindo basicamente o consumo interno. A produção deste material no Brasil é de 5,084 milhões de toneladas sendo 37\% para a indústria cimenteira, $52 \%$ para a construção civil, $9 \%$ para a indústria agrícola e $2 \%$ para outros fins, além disso, vem aumentando a demanda de gesso com o desenvolvimento do ramo da construção civil [4].

O beneficiamento da gipsita é essencial para a produção de gesso e varia de acordo com o tipo de gesso a ser produzido, adequadas a seu uso específico como revestimento, cerâmica ou fundição, para funções odontológicas, em restaurações e na moldagem de blocos e elementos ortodônticos [18].

A produção de gesso natural acontece basicamente em quatro etapas: extração de gipsita; preparação para calcinação; calcinação e seleção. Após a extração, a gipsita passa por alguns processos de beneficiamento para adequação ao tipo de forno onde será calcinada. Basicamente, as etapas são as seguintes: britagem, moagem grossa; estocagem; secagem; moagem fina e acondicionamento. A calcinação é o processo térmico pelo qual a gipsita é desidratada. O material é calcinado em uma faixa de temperatura de $140{ }^{\circ} \mathrm{C}$ a $160{ }^{\circ} \mathrm{C}$, para que $75 \%$ da água de cristalização seja retirada da estrutura para obter o hemidrato $\left(\mathrm{CaSO}_{4} \cdot 0,5 \mathrm{H}_{2} \mathrm{O}\right)$ [19].

A calcinação pode ser por via seca ou úmida. Se a gipsita for calcinada seca sob pressão atmosférica, ou baixa pressão, será obtido o hemidrato beta - $\beta$, caso a calcinação ocorra sob pressão de vapor de água saturante, será obtido o hemidrato alfa $\alpha$, ambos possuem a mesma fórmula química $\left(\mathrm{CaSO}_{4} \cdot 0,5 \mathrm{H}_{2} \mathrm{O}\right)$ [20].

$\mathrm{O}$ gesso consiste no sulfato de cálcio hemidratado, com fórmula química $\mathrm{CaSO}_{4} \cdot 0,5 \mathrm{H}_{2} \mathrm{O}$. $\mathrm{O}$ mesmo apresenta duas formas cristalinas distintas: gesso alfa $\alpha$ e gesso beta $\beta$; que se diferenciam pelo tamanho e forma do cristal [21].

O gesso $\alpha$, devido ao seu processo de produção apresenta aplicações mais nobres (gesso hospitalar) e consequentemente alcança preços mais elevados. O gesso $\beta$, com custo de produção mais baixo, predomina no gesso de construção nacional. A escolha do estudo focado no gesso $\beta$ é devido à grande abundância de jazidas de gipsita na região do pólo do Araripe e ao simples processo para a fabricação do gesso $\beta$, com baixo custo de produção. Juntando-se a isto, sua característica de fácil recristalização pela adição de água torna-o bastante atrativo para a indústria, que o emprega em variados produtos [22].

Segundo Teske et al. [23], as principais formas de utilização do gesso na construção civil são:

- $\quad 45 \%$ Pré-moldados (placas de gesso para tetos rebaixados, blocos de gesso e painéis)

- $51 \%$ Gesso para fundição de pré-moldados e para revestimento de paredes (aplicado manualmente com produção marginal de produtos aplicados por máquinas).

- $4 \%$ Moldes de cerâmica.

\section{RESÍDUOS INDUSTRIAIS - CLASSIFICAÇÃO}

A reciclagem de resíduos é uma alternativa econômica e ecologicamente viável, que diminui o impacto no meio ambiente, seja por minorar a quantidade de resíduos a descartar, seja por reutilizar os materiais poupando recursos naturais que, de outra maneira, seriam extraídos da natureza, notadamente no que concerne às matérias-primas para a construção civil [13]. Atualmente há um conceito chamado ecologia industrial que se trata de uma ferramenta que buscar orientar o setor industrial a fim de usar materiais e energia de forma sustentável e também reduzir a geração de resíduos. Esta ferramenta considera os resíduos industriais como sendo subprodutos ou materiais alternativos que podem alimentar outra indústria [1]. 
Em 2010 foi sancionada a Lei no 12.305 que institui a Política Nacional de Resíduos Sólidos (PNRS), dispondo sobre seus princípios, objetivos e instrumentos, bem como sobre as diretrizes relativas à gestão integrada e ao gerenciamento de resíduos sólidos, incluídos os perigosos, às responsabilidades dos geradores e do poder público e aos instrumentos econômicos aplicáveis. Esta lei visa principalmente não geração, redução, reutilização, reciclagem e tratamento dos resíduos sólidos, bem como disposição final ambientalmente adequada dos resíduos, além de estímulo à adoção de padrões sustentáveis de produção e consumo de bens e serviços; também trata como responsáveis todos os agentes envolvidos em todas as fases (fabricação, venda consumo) [24].

Muitas empresas estão começando a investir em pesquisas e novas tecnologias, buscando melhorar cada vez mais a qualidade dos produtos e propiciando uma maior eficiência do sistema produtivo. Assim a reutilização de resíduos ganha evidência, em virtude do volume crescente de resíduos sólidos e da dificuldade de se obter locais adequados para o descarte desses materiais, devido, principalmente ao aumento populacional [25].

O desenvolvimento sustentável contempla a ideia de atender às necessidades básicas de uma população sem comprometer a habilidade das gerações futuras atenderem suas próprias necessidades. Neste sentido, o desenvolvimento sustentável para o setor produtivo tem como implicação mais imediata a necessidade de se produzir a maior quantidade de bens com a menor quantidade de recursos naturais e a menor poluição, ou seja, o desenvolvimento econômico deverá ser desvinculado da geração de impactos ambientais [26].

\section{RESÍDUOS SÓLIDOS NA INDÚSTRIA DE ROCHAS ORNAMENTAIS}

$\mathrm{Na}$ indústria de rochas ornamentais, beneficiamento é dividido em: extração de blocos, desdobramentos de blocos, polimento, cortes e acabamentos finais. Segundo a NBR 10004, os resíduos de rochas ornamentais são classificados como classe II B (material inerte), em que se faz menção às rochas. No entanto, não se faz referência específica aos finos e lama gerados, com a mesma classificação, associa-se a ocorrência da silicose na exploração de rochas ornamentais [27]. Segundo a Resolução CONAMA n 307, o resíduo de granito é classificado como Classe A (reciclável) [28].

O principal resíduo gerado pela indústria de rochas ornamentais é o pó, que junto com água, gera a lama, o resíduo estocado no meio ambiente causa grande impacto ambiental. Muitos desses resíduos são descartados em cursos de água fazendo com que as propriedades da água sejam mudadas [29].

Uma alternativa de utilização desses resíduos gerados nos processos de beneficiamento de rochas ornamentais é incorporando esse material em outro, como por exemplo, na cerâmica vermelha, fazendo com que os impactos ambientais sejam minimizados [29].

A perda total no processo de beneficiamento de rochas ornamentais chega a variar de 20 a $25 \%$ do volume dos blocos, o pó das rochas é o principal resíduo gerado. Este pó é misturado com água e eventualmente outros acessórios na serragem das rochas, constituindo-se em um resíduo na forma de lama. A partir dos dados de perda no beneficiamento das rochas ornamentais, verifica-se que apenas no ano de 2013, no Brasil, foi gerado 2,06 milhões de toneladas de resíduo, deste total 1,02 milhão de toneladas de resíduo de granito, sendo 92.000 toneladas de lama apenas na fase de beneficiamento em marmorarias [30].

\section{RESÍDUOS SÓLIDOS NA INDÚSTRIA DE GESSO}

Segundo a NBR 10004, os resíduos de gesso são classificados como classe II A (material não inerte), em que podem ser solubilizados em água. Segundo a Resolução CONAMA n 307 (2002), o resíduo de gesso, era classificado, até 2010, como classe C, mas após um novo estudo no ano de 2011 o mesmo foi alterado a sua classificação (Resolução CONAMA n 431 de 2011) para resíduo classe B que engloba materiais recicláveis para outras destinações [31].

As principais fontes de resíduos de gesso na construção são as atividades de revestimento (88\%), as chapas de gesso acartonado (8\%) e os componentes pré-moldados $(4 \%)$, gerando, apenas na construção civil, um montante total de resíduos de gesso de 1,316 milhões de toneladas [4].

O resíduo de gesso pode ser encontrado em forma de pó ou torrões como é o caso do gesso de revestimento ou fosfogesso (gesso gerado da indústria de fertilizantes) onde para a sua reutilização, normalmente, é necessário o seu peneiramento para a granulometria necessária; ou em forma de pedaços ou partes maiores como é o caso de chapas para drywall, placas e ornamentos de gesso, onde para sua reutilização é necessária a trituração, moagem e peneiramento dos mesmos.

Os resíduos de gesso podem ter três destinações principais: serem utilizados como ingredientes (na proporção de 5\%) da produção de cimento, no qual o gesso atua como retardador de pega; voltar às fábricas 
para reaproveitamento nos respectivos processos produtivos; e ser transformados em gesso para agricultura, para ser usado como corretor de $\mathrm{pH}$ do solo. A alternativa de incorporar esse material em outro é relativamente nova, principalmente devido à mudança recente de classe [30].

\section{UTILIZAÇÃO DE RESÍDUOS SÓLIDOS NA INDÚSTRIA CERÂMICA}

A indústria de cerâmica vermelha tem grande potencial de reciclar resíduos de diversos locais, haja vista que possui grande quantidade de matéria prima básica, neste caso a argila. Assim, os resíduos, principalmente os finos, podem ser adicionados à massa cerâmica base, diminuindo a possibilidade de acondicionamento incorreto dos mesmos, minimizar impactos negativos ao meio ambiente e em alguns casos melhorar as características do produto final. Neste sentido esta indústria tem boa capacidade de reciclagem de resíduos.

A heterogeneidade dos materiais da indústria de cerâmica vermelha (argilas e massas), e também as técnicas de processamento simples (principalmente extrusão e prensagem) para fabricação dos produtos, como blocos de vedação e telhas, facilitam a incorporação de resíduos nas composições, e estudos comprovam a obtenção de peças com especificações quem as normas técnicas estabelecem [32].

Os resíduos sólidos podem ser classificados de acordo com as suas propriedades iniciais e do modo como alteram as características do produto cerâmico final, assim podem ser: fundente, cinza volante, radioativo, redutor de plasticidade, combustível, entre outros. A influência nas características de um corpo cerâmico depende também de como o material será conformado (extrusão ou prensagem), da quantidade utilizada em uma formulação e da variedade de tipos de matéria prima, o que torna esse tipo de padronização ainda muito complexo [33].

A indústria de cerâmica vermelha pode absorver diversos tipos de resíduos industriais, podendo este, se tornar matéria prima, o que está cada vez mais em evidência. Assim, de acordo com a origem do material e de como o mesmo deve ser tratado, qualquer tipo de resíduo de indústria (indústria da construção civil, indústria de celulose, resíduos de construção e demolição, indústria de transformação de rochas e metais, entre outro) pode ser utilizado para produzir corpos cerâmicos [34].

\subsection{Efeitos de resíduos de granito em cerâmica vermelha}

Conforme foi apresentado anteriormente, os resíduos de granito são classificados como inertes e recicláveis, podendo ser utilizado como material incorporado à massa cerâmica. A sua utilização como material desta natureza está condicionada à sua granulometria, normalmente encontrada em forma de pó, assim o resíduo de granito classifica-se como material redutor de plasticidade, podendo provocar mudanças nas propriedades mecânicas, retração e absorção de água do produto de cerâmica vermelha formado.

Outro ponto importante do efeito da utilização dos resíduos de granito é a possibilidade do aumento da dureza e densificação dos produtos de cerâmica vermelha, devido ao enriquecimento da massa de argila com o quartzo presente no resíduo de granito e também pela formação de maior quantidade de fase vítrea.

Nesta parte são apresentados trabalhos realizados na área de aproveitamento de resíduos de granito em cerâmica vermelha com seus resultados obtidos.

Alexandre et al. [35] avaliaram a degradação sofrida pela cerâmica de argila incorporada com 5 e $10 \%$ em peso de um resíduo de granito sob intemperismo durante 6, 8 e 10 meses. Em geral, as dimensões lineares tendem a aumentar com o tempo e a temperatura de queima, além disso, o aumento da temperatura de queima provocou a redução da absorção de água.

Taguchi et al. [29] avaliaram as propriedades tecnológicas de cerâmica vermelha incorporada com resíduo de rocha ornamental proveniente do tear de fio diamantado e mostrou que o aumento da temperatura provocou o aumentou da densidade e da tensão de ruptura das peças e reduziu-se a absorção de água. Além disso, observou-se uma redução na retração linear com aumento da fração de resíduo na massa cerâmica. Os resultados mostraram que as amostras (com 20\%, $40 \%$ e $60 \%$ de teor de resíduo) podem ser empregadas na fabricação de telhas e blocos de cerâmica vermelha estrutural, pois possuem propriedades tecnológicas superiores ao indicado pelas normas técnicas dessas classes de produtos [28].

Mendonça et al. [36] realizaram um estudo sobre a expansão por umidade a partir de indução pelo método de autoclavagem em blocos cerâmicos obtidos a partir de massas incorporadas com resíduos de caulim e granito e mostrou que os resíduos de caulim e de granito (20\% de incorporação) apresentam características similares às matérias-primas cerâmicas convencionais não plásticas (feldspato e quartzo), e que produtos cerâmicos submetidos a temperaturas de queima mais elevadas $\left(800{ }^{\circ} \mathrm{C}\right.$ para $\left.900{ }^{\circ} \mathrm{C}\right)$ apresentam melhores resultados de expansão por umidade, melhorando assim o material.

Vieira et al. [37] utilizaram granito em massa cerâmica para telhas e mostraram que a adição de grani- 
to $(5 \%$ a $30 \%)$ à massa cerâmica vermelha contribuiu para diminuição da plasticidade e redução nos valores de absorção de água. Entretanto, com o aumento na adição de granito, ocorreu uma brusca diminuição da resistência mecânica das peças queimadas $\left(950^{\circ} \mathrm{C}\right)$. Os resultados mostraram que é preciso diminuir a granulometria do granito para evitar o surgimento de trincas nas peças.

Silva et al. [38] usaram técnicas estatísticas para modelar a resistência à flexão de corpos cerâmicos contendo resíduo de granito e mostraram que a adição de granito (0 a 50\%), provoca, de forma geral, o decréscimo do módulo de ruptura à flexão dos corpos cerâmicos. O aumento da temperatura de queima possibilita elevar os teores de resíduos incorporados às formulações, podendo-se atingir teores superiores a $50 \%$ de resíduo de granito sem o decréscimo do módulo de ruptura quando da queima a $1.150{ }^{\circ} \mathrm{C}$. $\mathrm{O}$ incremento no teor de argila (material plástico) conduziu ao aumento do módulo de ruptura à flexão independentemente da temperatura de queima.

Menezes et al. [39] utilizaram resíduo do beneficiamento de serragem de granito para produção de blocos e telhas cerâmicos. Os resíduos foram caracterizados e foram formuladas composições contendo os resíduos e confeccionados corpos de prova por extrusão. Os corpos de prova foram queimados e em seguida determinou-se sua absorção de água e módulo de ruptura à flexão. Concluiu-se que é possível a incorporação de até $50 \%$ de resíduo em formulações para produção de blocos e telhas cerâmicas e que a utilização do resíduo de granito e de caulim possibilita obter propriedades físicas superiores às observadas nos corpos de prova com incorporação apenas de resíduo de caulim.

Menezes et al. [40], em outro trabalho, avaliaram as possibilidades de utilização dos resíduos da serragem de granitos gerados pelas indústrias de beneficiamento da Região Nordeste, como matéria-prima cerâmica alternativa na produção de blocos e revestimentos cerâmicos. Foi realizada a caracterização e em seguida os ensaios tecnológicos com composições cerâmicas. Os resultados mostraram que os resíduos (teores de resíduos nas proporções de 20\%, 25\%, 30\%, 35\%, 40\%, 45\%, 50\%, 55\% e 60\%) apresentam características físicas e mineralógicas semelhantes as das matérias-primas cerâmicas convencionais. Além disso, os blocos confeccionados com teores de até 50\% de resíduos apresentam características cerâmicas dentro das especificações da normalização; as massas cerâmicas com adições de resíduo podem ser usadas na confecção de revestimentos enquadrados nos grupos BI, BIIb, BIIa e BIII dependendo da temperatura de queima e que nas condições de queima das indústrias de queima rápida os produtos apresentam características referentes ao grupo BIII.

Acchar et al. [41] descreveram a variação do comportamento de uma argila utilizada em uma indústria de cerâmica vermelha, resultante de adições de uma lama de mármore e granito, tal como é produzida em uma indústria de beneficiamento de pedras ornamentais do estado do Rio Grande do Norte. Misturas de argila e resíduo (10 - 50\% em peso) foram compactadas uniaxialmente e sinterizadas a temperaturas entre 950 e $1150{ }^{\circ} \mathrm{C}$. Os resultados obtidos por análise química e mineralógica (DRX e FRX), análises térmicas (DTA, TG e dilatometria), medidas de distribuição granulométrica, porosidade, absorção de água e tensão de ruptura à flexão, revelam que a lama de mármore e granito pode ser incorporada na massa de argila sem perda ou comprometimento das propriedades dos corpos sinterizados de cerâmica vermelha.

Moreira et al. [42] utilizaram um resíduo de serragem de granito, proveniente da indústria de pedras ornamentais do estado do Espírito Santo, como aditivo na fabricação de produtos cerâmicos para construção civil. As amostras foram caracterizadas e preparadas misturas contendo até $10 \%$ em peso de resíduo, e sinterizadas em sete diferentes temperaturas entre $850{ }^{\circ} \mathrm{C}$ e $1150{ }^{\circ} \mathrm{C}$. As propriedades físico-mecânicas foram determinadas em função da temperatura de sinterização e porcentagem de resíduo adicionado. Os resultados revelaram que uma série de transformações de fases ocorreram durante a sinterização. Além do mais, os corpos sinterizados contendo resíduo de serragem de granito têm uso provável em cerâmica vermelha, contribuindo para a minimização de resíduos e desenvolvimento autossustentado.

Torres et al. [43] incorporaram resíduos das indústrias de corte e polimento de granito para produção de telhas. Inicialmente as massas cerâmicas foram caracterizadas e as formulações mais promissoras foram selecionadas, os resultados obtidos mostraram que a incorporação de $10 \%$ em peso de resíduo de granito às telhas apresentou excelentes propriedades, em relação a resistência mecânica e absorção de água. Concluiuse que o resíduo de granito substitui parcialmente a matéria-prima em formulações cerâmicas tradicionais, contribuindo para a preservação dos recursos naturais não renováveis.

Segadães et al. [44] analisaram resíduos de mármores e granitos utilizados para melhorar os produtos de cerâmica. $\mathrm{O}$ trabalho mostrou as alterações nas propriedades de uma mistura industrial à base de argila (cerâmica vermelha), já em uso na produção de piso azulejos, com as adições de resíduos de corte de pedra ornamental (mármore e granito). As amostras contendo até $30 \%$ em peso foram sinterizadas em um forno eléctrico $\left(1100-1150{ }^{\circ} \mathrm{C}\right.$, durante $2 \mathrm{~h}$ ) e os resultados obtidos apontam o efeito que as adições de resíduo de 
granito têm sobre o comportamento da mistura de argila e mostram como as propriedades dos produtos sinterizados de argila podem ser melhoradas, com a possibilidade de usar temperaturas mais baixas de queima.

Segadães et al. [45] utilizaram resíduos de corte de rocha ornamental como matéria-prima para produtos cerâmicos de cerâmica vermelha, com ênfase em propriedades e microestrutura. $\mathrm{O}$ trabalho foi realizado com a adição de dois diferentes resíduos de corte de rocha ornamental (granito e mármore + granito), todos os materiais foram recolhidos em locais industriais e o comportamento de misturas contendo $70 \%$ em peso de argila $+30 \%$ em peso de resíduos é bem destacado. Amostras de pó foram prensadas, sinterizadas em um forno eléctrico durante $2 \mathrm{~h}$ a uma temperatura na gama de $950-1150{ }^{\circ} \mathrm{C}$, e caracterizadas. Os resultados experimentais obtidos (retração de queima, porosidade, resistência à flexão, microestrutura) mostram que os resíduos podem ser usados e auxiliam o processo de sinterização e simultaneamente controlando a plasticidade e a retração da argila.

\subsection{Efeitos de resíduos de gesso em cerâmica vermelha}

Os resíduos de gesso são classificados como não inertes (pois se solubilizam em água) e recicláveis para outras destinações, podendo ser utilizado como material incorporado à massa cerâmica. A sua utilização como material desta natureza está condicionada à sua granulometria, onde o resíduo pode passar por moagem e peneiramento de acordo com a condição e tipo, além disso, o mesmo classifica-se também como material redutor de plasticidade, podendo provocar mudanças nas propriedades mecânicas, retração e absorção de água do produto de cerâmica vermelha formado [24].

Nesta parte são apresentados trabalhos realizados na área de aproveitamento de resíduos de gesso em cerâmica vermelha com seus resultados obtidos.

Testolin et al. [46] analisaram a incorporação de resíduos de gesso (obtidos de um canteiro de obras) na produção de blocos de cerâmica e os resultados mostraram que a adição de $20 \%$ de resíduos de gesso aos blocos é um substituto viável para a argila na indústria cerâmica e os testes aplicados neste estudo provaram ser uma ferrementa importante para a avaliação técnica e ambiental deste processo de reciclagem. A adição do resíduo de gesso até esta proporção apresentou propriedades do produto dentro de limites aceitáveis aos padrões para a produção de blocos cerâmicos.

Nawi et al. [47] analisaram a alteração das propriedades físicas da cerâmica devido à adição de diferentes quantidades de gesso em pó. $\mathrm{O}$ objetivo do trabalho foi contribuir para a proteção do meio ambiente e a demonstração de uma oportunidade de utilização do gesso. O gesso inicialmente era usado como molde de peças para indústria cerâmica e, após o descarte, os resíduos foram triturados, muídos e por fim peneirados para serem utilizados como enchimento em massa cerâmica. Os corpos de prova foram produzidos a partir da queima a $950{ }^{\circ} \mathrm{C}, 1000{ }^{\circ} \mathrm{C}$ e $1050{ }^{\circ} \mathrm{C}$ e com porcentagem em peso diferente de incorporação de resíduo $(0 \%$, $2 \%, 4 \%, 6 \%, 8 \%$ e $10 \%$ em peso) na composição. Os testes e exames realizados apontaram bons resultados em relação às propriedades características da cerâmica como tamanho de partícula, retração, porosidade e densidade. Os resultados mostram que o resíduo de gesso pode ser usado como enchimento em cerâmica.

Paskocimas et al. [48] avaliaram a incorporação de resíduos de gesso de construção (gesso usado em revestimento de paredes) em formulações de massa para cerâmica vermelha de argilas provenientes do município de Assú-RN e mostrou que as melhores propriedades tecnológicas foram obtidas nas formulações que possuiam argilas medianamente plásticas em sua composição. Os percentuais de resíduo até 15\%, incorporados na matriz cerâmica com queima a $950{ }^{\circ} \mathrm{C}$ obtiveram os melhores resultados em termos de propriedades tecnológicas.

Cipriano et al. [49] avaliaram os efeitos da incorporação de resíduo de gesso da indústria de placas em argila residual obtida da extração da gipsita, para obtenção de produtos de cerâmica vermelha. Foi avaliada a incorporação de $5 \%$ e $10 \%$ de resíduos de gesso na argila, considerando duas temperaturas de sinterização (800 e $1050{ }^{\circ} \mathrm{C}$ ), os resultados mais significativos foram obtidos com a adição de $5 \%$ de resíduo de gesso queimadas a $800^{\circ} \mathrm{C}$ apresentando propriedades semelhantes à argila pura. A utilização de materiais residuais permite a redução dos impactos ambientais e a possibilidade de novas formulações para produtos de cerâmica vermelha.

Radulović et al. [50] investigaram propriedades físicas, a composição química e comportamento térmico dos resíduos de gesso, com objetivo de avaliar a viabilidade do uso de resíduos de gesso e avaliar a viabilidade do processo de reciclagem. Os resultados indicam que a reutilização de resíduos de gesso pode fornecer um substituto viável para argila na indústria cerâmica e também que a reaplicação do gesso, após reciclagem, é possível tanto por fatores econômicos quanto aspectos ambientais.

Contreras et al. [51] avaliaram o uso de fosfogesso (gesso gerado durante a fabricação de ácido fosfó- 
rico nas indústrias de fertilizantes) obtido em pilhas de descarte e moído como um aditivo na fabricação de cerâmica. Os corpos de prova cerâmicos foram confeccionados incorporando diferentes concentrações de fosfogesso $\left(5,7,5\right.$ e $10 \%$ em peso) à argila natural e queimado a $950{ }^{\circ} \mathrm{C}, 1050{ }^{\circ} \mathrm{C}$ e $1150{ }^{\circ} \mathrm{C}$, e foram avaliadas as propriedades físicas, químicas e tecnológicas. Os resultados apontaram que o uso do fosfogesso incorporado à massa cerâmica é possível e melhora o comportamento de sinterização e a resistência à flexão.

Melo e Silva [52] estudaram a aplicação do fosfogesso (doado pela empresa produtora de fertilizantes fosfatados) na fabricação de materiais cerâmicos. Inicialmente foi realizada a revisão bibliográfica sobre o assunto, e em seguida foram realizados testes laboratoriais quanto à adição do resíduo fosfogesso na proporção de $5 \%, 10 \%$ e $15 \%$ na confecção de tijolos maciços e blocos cerâmicos. Os corpos de prova foram confeccionados por prensagem e queimados a $1000{ }^{\circ} \mathrm{C}$, então foi realizada a análise macroestrutural e de tensão de ruptura a flexão. Os resultados mostram a viabilidade do uso do fosfogesso em produtos cerâmicos, podendo o material com tais características ser empregado na fabricação de tijolos, além de não apresentarem trincas ou rachaduras nos corpos de prova.

Silva et al. [53] verificou o efeito da incorporação do resíduo de gesso proveniente revestimento de paredes da construção civil moído, na formulação de massas para cerâmica vermelha. As matérias-primas foram coletadas de dois pólos cerâmicos do Estado do Rio Grande do Norte e formuladas com o intuito de obter aquelas com as melhores propriedades físicas e mecânica, tendo sido incorporados os percentuais 5\%, $10 \%, 15 \%, 20 \%, 25 \%$ e $30 \%$ de resíduo, na melhor formulação da indústria cerâmica. As amostras foram sinterizadas às temperaturas de $850^{\circ} \mathrm{C}, 950{ }^{\circ} \mathrm{C}$ e $1050{ }^{\circ} \mathrm{C}$ e submetidas a ensaios tecnológicos. Os melhores resultados de incorporação do resíduo nas formulações de massa de cerâmica vermelha foram observados na faixa de temperatura de $850{ }^{\circ} \mathrm{C}$ a $950{ }^{\circ} \mathrm{C}$, naquelas que possuem argilas ilíticas e medianamente plásticas em sua composição, na faixa de $0 \%$ a $15 \%$ de resíduo incorporado.

Duarte e Fernandes [54] analisaram a adição de fosfogesso (doado por empresa produtora de fertilizantes fosfatados) em cerâmica vermelha para fabricação de tijolos, inicialmente foi realizada a caracterização do resíduo de fosfogesso, então foi realizada a incorporação na proporção de $15 \%$ e $30 \%$ em massa de argila. Os corpos de prova foram confeccionados por extrusão e queimados a temperatura de $950{ }^{\circ} \mathrm{C}$, sem seguida foi realizado o ensaio de tensão de ruptura a flexão. Os resultados apontaram melhora na resistência dos corpos de prova estudados, neste sentido a conclusão foi que a mistura fosfogesso e argila torna-se viável a utilização do mesmo na produção de tijolos.

Rakhila et al. [55] realizou o desenvolvimento de um material cerâmico que une argila e fosfogesso (doado por indústria de fosfato e peneirado). Inicialmente foi realizada a caracterização das matérias primas, em seguida as mesmas foram misturadas com adição de fosfogesso em vários níveis (de 0 a $50 \%$ em peso de argila). Corpos de provas foram confeccionados por prensagem e em seguida queimado a $1100{ }^{\circ} \mathrm{C}$. Os resultados obtidos mostraram que a cerâmica com $40 \%$ de incorporação de PG satisfez com sucesso os requisitos das normas. $\mathrm{O}$ estudo concluiu que o material é um bom isolante térmico e resistente a ácidos de natureza mecânica e de acordo com as propriedades permite integrar o fosfogesso na composição da cerâmica

Lima et al. [56] apresentou a aplicação de resíduos de gipsita (coletadas em uma empresa mineradora e já obtida em granulometria adequada) em formulações de massas cerâmicas. Inicialmente foi realizada a caracterização do resíduo. Foram confeccionados corpos de prova com incorporação de resíduo de gipsita de $5 \%$ em peso, foram queimados nas temperaturas de $1200{ }^{\circ} \mathrm{C}$ e $1250{ }^{\circ} \mathrm{C}$ e em seguida foram realizados ensaios tecnológicos com os mesmos. Os resultados apontam a possibilidade de aproveitamento deste material na obtenção de materiais cerâmicos, apresentando-se dentro das exigências das normas vigentes.

Pereira e Monteiro [57] analisaram a adição de resíduos de gesso (doado por empresa coletora de resíduos e peneirado em laboratório) gerados pelo setor da construção civil, em massas cerâmicas para fabricação de revestimentos. As massas cerâmicas receberam adição do resíduo de gesso nas proporções de 1\%, 5\% e $10 \%$. Os corpos de prova foram confeccionados através da compactação uniaxial, foram queimadas nas temperaturas de $1000{ }^{\circ} \mathrm{C}, 1100{ }^{\circ} \mathrm{C}$ e $1200{ }^{\circ} \mathrm{C}$, e então foram realizados ensaios tecnológicos. Os resultados dos ensaios tecnológicos apontaram que a adição de resíduo de gesso em massas cerâmicas para revestimentos é viável, especificamente para produção de materiais porosos. Contudo, as formulações com $1 \%$ e $5 \%$ obtiveram os melhores resultados.

Silva et al. [58] estudaram a incorporação de resíduos de gesso de revestimento na formulação de massa para cerâmica vermelha. A massa cerâmica recebeu adição do resíduo de gesso nas proporções de 5\%, $10 \%$ e $15 \%$. Os corpos de prova foram confeccionados através da compressão uniaxial, foram queimadas nas temperaturas de $850{ }^{\circ} \mathrm{C}, 950{ }^{\circ} \mathrm{C}$ e $1050{ }^{\circ} \mathrm{C}$, e então foram realizados ensaios tecnológicos e micrografias. Os resultados dos ensaios tecnológicos mostraram que a incorporação de $5 \%$ de resíduos com queima a $950{ }^{\circ} \mathrm{C}$ obteve os melhores resultados e conclui-se que a adição de resíduos de gesso em massa para indústria de ce- 
râmica tem efeito positivo do ponto de vista tecnológico, econômico e ambiental.

\section{CONCLUSÃO}

Atualmente, a necessidade de reciclagem de resíduos industriais tem estado sempre em evidência e a indústria de cerâmica vermelha tem grande possibilidade de absorver resíduos como o granito e o gesso, a partir de sua caracteristica heterogênea e volume de produção.

No Brasil, ainda são escassos estudos relevantes e pesquisas na área de reciclagem de resíduos, quando se leva em consideração a sua enorme quantidade produzida e que é descartada anualmente pelas indústrias. Não foram encontradas pesquisas que utilizassem os resíduos de granito e gesso de forma conjunta em massa cerâmica, apenas de formas separadas, o que pode ser uma sugestão para possíveis trabalhos futuros.

Os resultados das pesquisas apontam que o uso de resíduos de granito e gesso na indústria de cerâmica vermelha é uma alternativa viável para o aumento da qualidade técnica do produto cerâmico e o melhora da qualidade ambiental. $\mathrm{O}$ uso do granito e do gesso na produção cerâmica além de contribuir com a qualidade do meio ambiente, diminuindo assim os impactos ambientais negativos que possam ser causados por estes resíduos, apresentou resultados dentro dos padrões estabelecidos pelas legislações vigentes.

Os trabalhos não apontaram a utilização dos resíduos para produção em escala industrial, evidenciando a necessidade de conscientização de empresas sobre a potencialidade de utilização de resíduos em massas cerâmicas. Outro ponto importante foi a grande quantidade de resíduos gerados pelas indústrias de gesso e de granito que ainda não possuem maneiras adequadas para o seu acondicionamento e principalmente para sua reciclagem, se tornando, assim, fontes de poluição ambiental, o que ratifica a necessidade de leis e fiscalização para as indústrias que geram estes resíduos e maior incentivo à reciclagem ou reutilização dos mesmos.

\section{AGRADECIMENTOS}

Os autores agradecem ao Instituto Federal Campus Floriano e Campus Teresina Central, ao Centro de Tecnologia do Gás - Rio Grande do Norte, à Cerâmica Vitória em Oeiras - PI e a todos quem direta ou indiretamente contribuíram para realização deste trabalho.

\section{BIBLIOGRAFIA}

[1] INOCENTE, J. M., NANDI, V. S., ROSSO F., et al., "Estudo de Recuperação de Resíduos Vítreos na Formulação de Cerâmica Vermelha", Cerâmica Industrial, v. 23, n. 3, pp. 34-39, Jul. 2018.

[2] MONTEIRO, S. N., VIEIRA, C. M. F., "Effect of oily waste addition to clay ceramic", Ceramics International, v. 31, n. 2, pp. 353-358, Set. 2005.

[3] ASSOCIAÇÃO BRASILEIRA DA INDÚSTRIA DE ROCHAS ORNAMENTAIS, Setor de rochas ornamentais e de revestimento situação atual, demandas e perspectivas frente ao novo marco regulatório da mineração brasileira, São Paulo, ABIROCHAS, 2016.

[4] SINDICATO DAS INDÚSTRIAS DE EXTRAÇÃO E BENEFICIAMENTO DE GIPSITA, CALCÁREOS, DERIVADOS DE GESSO E DE MINERAIS NÃO-METÁLICOS DO ESTADO DE PERNAMBUCO, Informações Técnicas, Recife, SINDUSGESSO, 2016.

[5] ROCHA, R. D. C., ZOREL, H. E., LANDO, T., "Use of experimental design in the study of galvanic sludge immobilization in red ceramic for environmental impact minimization", Cerâmica, v. 63, n. 365, pp. 1-10, Jan. 2017.

[6] SINDICATO DA INDÚSTRIA DA CERÂMICA VERMELHA, Cartilha de Informações Técnicas 2017, Brasília, SINDICER, 2017.

[7] ALMEIDA, K. S., MOURA, C. S., SOARES, R. A. L., "Análise dos impactos ambientais gerados pela indústria de cerâmica vermelha no Piauí", Cerâmica Industrial, v. 19, n. 5, pp. 33-34, Set. 2014.

[8] ASSOCIAÇÃO BRASILEIRA DE CERÂMICA, Cerâmica no Brasil - números do setor-cerâmica vermelha, Brasília, ABC, 2017.

[9] FEDERAÇÃO DAS INDÚSTRIAS DO ESTADO DE MINAS GERAIS, Guia Técnico Ambiental da Indústria de Cerâmica Vermelha, Minas Gerais, FIEMG, 2015.

[10] ASSOCIAÇÃO NACIONAL DA INDÚSTRIA DE CERÂMICA, Indústria cerâmica. Informações Técnicas, Brasília, ANICER, 2016. 
[11] IPT - INSTITUTO DE PESQUISAS TECNOLÓGICAS DO ESTADO DE SÃO PAULO, "Estudo Estratégico da Cadeia Produtiva da Indústria Cerâmica no Estado de São Paulo", Relatório Técnico, São Paulo, IPT, 2018.

[12] SILVA, R. G., SILVA, V. P., "Cleaner production: practical and theoretical contributions for the sustainability of the red ceramic", Cerâmica, v.63 n.368, pp. 494-507, Out. 2017.

[13] CAVALCANTI, L. F. M., OLIVEIRA, F. M. C., MELO, E. B., et al., "Granito Azul Sucuru: caracterização tecnológica por meio do aproveitamento do material", Revista Principia, n. 33 pp. 11-20, Mai. 2017.

[14] VIDAL, F. W. H., AZEVEDO, H. C. A., CASTRO, N. F., Tecnologia de rochas ornamentais: pesquisa, lavra e beneficiamento, 1 ed., Rio de Janeiro, CETEM/MCTI, 2014.

[15] TCHADJIÉ, L. N., RANJBAR, N., DJOBO, J. N. Y., et al., "Potential of using granite waste as raw material for geopolymer synthesis", Ceramics International, v. 42, n. 2, pp. 3046-3055, Fev. 2016.

[16] ASSOCIAÇÃO BRASILEIRA DE NORMAS TÉCNICAS, NBR-6502 Rochas e Solos - Especificação, Rio de Janeiro, ABNT, 1995.

[17] ALENCAR, C. R. A., Manual de caracterização, aplicação, uso e manutenção das principais rochas comerciais no Espírito Santo: rochas ornamentais, Instituto Euvaldo Lodi - Regional do Espírito Santo. Cachoeiro de Itapemirim/ES, 2013.

[18] OLIVEIRA, F., BORGES, L., MELO, E., BARROS, M., "Características Mineralógicas e Cristalográficas da Gipsita do Araripe", HOLOS, a. 28, v. 5, pp. 71-82, Nov.2012.

[19] LIRA, C. P. L., AMARAL, A. J. R., DANTAS, J. O. C., et al., Gipsita, Balanço Mineral Brasileiro, Brasília, DNPM/PE, 2015.

[20] BEZERRA, M. S., Gipsita Relatório Técnico, Brasília, Ministério de Minas e Energia - MME, 2009.

[21] BARBOSA, A., FERRAZ, A. V., SANTOS, G. A., "Caracterização química, mecânica e morfológica do gesso $\beta$ obtido do pólo do Araripe", Cerâmica, v. 60, n. 356, pp. 501-508, Ago. 2014.

[22] GAZQUES, M. J., BOLIVAR, J. P., VACA, F., et al., "Evaluation of the use of TiO2 industry red gypsum waste in cement production", Cement \& Concrete Composites, v. 37, pp. 76-81, Mar. 2013.

[23] TESKE, S., GONÇALVES, P. F. A., NAGALLI, A., "Development of a conceptual model of an ecologic tile using building gypsums waste”, Cerâmica, v. 61, n.358, pp. 190-198, Abr.- Jun. 2015.

[24] BRASIL, Lei 12.305 de 02 de agosto de 2010. Política Nacional de Resíduos Sólidos (PNRS), Brasília, Diário Oficial da União - DOU, 2010.

[25] GARCIA, M. B. S., LANZELLOTTI NETO, J., MENDES, J. G., et al., "Resíduos Sólidos: Responsabilidade Compartilhada", Semioses, v. 9, n. 2, pp. 77-91, Jul./Dez. 2015.

[26] BRASILEIRO, L. L., MATOS, J. M. E., "Revisão bibliográfica: reutilização de resíduos da construção e demolição na indústria da construção civil", Cerâmica, v. 61, n.358, pp.178-189, Mar. 2015.

[27] ASSOCIAÇÃO BRASILEIRA DE NORMAS TÉCNICAS, NBR 10004 Resíduos Sólidos - Classificação, Rio de Janeiro, ABNT, 2004.

[28] BRASIL. MINISTÉRIO DO MEIO AMBIENTE, Resolução CONAMA no 307, de 5 de julho de 2002. Estabelece diretrizes, critérios e procedimentos para a gestão dos resíduos da construção civil, Brasília, Diário Oficial da União - DOU, 2002.

[29] TAGUCHI, S. P., SANTOS, J. C., GOMES, T. M., et al., "Avaliação das propriedades tecnológicas de cerâmica vermelha incorporada com resíduo de rocha ornamental proveniente do tear de fio diamantado", Cerâmica, v. 60, n. 354, pp. 291-296, Ago. 2014.

[30] KUMAYAMA, R., ALCANTARA, M. A. M., CRUZ, W. S., et al., "Estudo da viabilidade do emprego de pó de mármore para produção de concreto autoadensável e substituição parcial dos agregados por pérolas de poliestireno expandido (EPS)", REEC - Revista Eletrônica de Engenharia Civil, v. 10, n. 5, pp. 56-71, Set. 2015.

[31] BRASIL. MINISTÉRIO DO MEIO AMBIENTE, Resolução CONAMA no 431, de 24 de maio de 2011, Altera o art. $3^{\circ}$ da Resolução $n^{\circ} 307$, de 5 de julho de 2002, do Conselho Nacional do Meio Ambiente - CONAMA, estabelecendo nova classificação para o gesso, Brasília, Diário Oficial da União - DOU, 2011.

[32] CARREIRO, M. E. A., SANTOS, R. C., SILVA, V. J., et al., "Resíduo de quartzito - matéria-prima alternativa para uso em massas de cerâmica estrutural", Cerâmica, v. 62, n. 362, pp. 170-178, Dez. 2016. 
[33] FERREIRA, S. B., DOMINGUES, P. C., SOARES, S. M., et al., "Recycled Gypsum and Red Ceramic Waste Based Mortars", International Journal of Engineering and Technology, v. 7, n. 3, pp. 209-214, Jun. 2015.

[34] BABISK, M. P., VIDAL, F. W. H., RIBEIRO, W. S., et al., "Incorporação de resíduo de quartzitos em cerâmica vermelha”, HOLOS, a. 28, v. 6, pp. 169-177, Set. 2012.

[35] ALEXANDRE, J., AZEVEDO, A. R. G., XAVIER, G. C., et al., "Influence of Weather Exposure on Dimensional Changes in Clay Ceramics Incorporated with Granite Residue", Materials Science Forum, v. 869, pp. 131-135, Ago. 2016.

[36] MENDONÇA, M. G. D., SANTANA, L. N. L., NEVES, G. A., et al., "Estudo da Expansão por Umidade Através de Indução pelo Método de Autoclavagem em Blocos Cerâmicos Obtidos a partir de Massas Incorporadas com Resíduos de Caulim e Granito", Cerâmica Industrial, v. 16, n. 2, pp. 35-39, Mar/Abr. 2011.

[37] VIEIRA, M. F., PEÇANHA, L. A., MONTEIRO, S. N., "Reformulation of roofing tiles body with addition of granite waste from sawing operations", Journal of the European Ceramic Society, v. 24, n. 8, pp. 2349-2356, Jul. 2004.

[38] SILVA, B.J., MENEZES, R. R. I., SANTANA, L. N. L. I., et al., "Uso de técnicas estatísticas para modelar a resistência à flexão de corpos cerâmicos contendo resíduo de granito", Revista Matéria, v.17, n.1, pp.919-930, Jan. 2012.

[39] MENEZES, R., NEVES, G. A., FERREIRA, H. C. O., "Use of granite sawing wastes in the production of ceramic bricks and tiles", Journal of the European Ceramic Society, v. 25, n. 7, pp. 1149-1158, Mai. 2005.

[40] MENEZES, R. R., NEVES, G. A., FERREIRA, H. C., "Uso de rejeitos de granitos como matériasprimas cerâmicas", Cerâmica, v. 48, n. 306, pp. 92-101, Abr./Mai./Jun. 2002.

[41] ACCHAR, W., SILVA, M., VIEIRA, F.A., et al., "Effect of marble and granite sludge in clay materials", Materials Science and Engineering, v. 419, n. 1, pp. 306-309, Mar. 2006.

[42] MOREIRA, J. M. S., FREIRE, M. N., HOLANDA, J. N. F., "Utilização de resíduo de serragem de granito proveniente do estado do Espírito Santo em cerâmica vermelha", Cerâmica, v.49, n. 312, pp.262-267, Out. 2003.

[43] TORRES, P., FERNANDES, H. R., OLHERO, F., et al., "Incorporation of wastes from granite rock cutting and polishing industries to produce roof tiles", Journal of the European Ceramic Society, v. 29, n. 1, pp. 23-30, Jan. 2009.

[44] SEGADÃES, M., CARVALHO, M. A., ACCHAR, W., "Using marble and granite rejects to enhance the processing of clay products", Applied Clay Science, v. 30, n. 1, pp. 42-52, Ago. 2005.

[45] SEGADÃES, M., VIEIRA, F. A., ACCHAR, W., "Using ornamental stone cutting rejects as raw materials for red clay ceramic products: Properties and microstructure development", Materials Science and Engineering, v. 435-436, n. 5, pp. 606-610, Nov. 2006.

[46] TESTOLIN, R. C., GODINHO-CASTRO, A. P., JANKE, L., et al., "Incorporation of gypsum waste in ceramic block production: Proposal for a minimal battery of tests to evaluate technical and environmental viability of this recycling process", Waste Management, v. 32, n.1, pp. 153-157, Jan. 2012.

[47] NAWI, M., BADARULZAMAN, N. A., "Effect of Gypsum of Paris Waste and Sintering Temperatures on Physical Properties of Pottery", Procedia CIRP, v. 26, pp. 752-755, Jan. 2015.

[48] PASKOCIMAS, A., SILVA, J. B., LUZ, J. C., et al., "Avaliação da incorporação de resíduos de gesso de construção em formulações de massa para cerâmica vermelha de argilas provenientes do município de Assú-RN", In: 52 ${ }^{\circ}$ Congresso Brasileiro de Cerâmica, Florianópolis, Jun. 2008.

[49] CIPRIANO, P. B., REZENDE, R. T. O., FERRAZA, A. V., "Produção de cerâmica vermelha utilizando argila da mineração de gipsita e resíduo de gesso", Acta Brasiliensis, v. 3, n. 1, pp. 25-29, Jan. 2019.

[50] RADULOVIĆ, D., TERZIĆ, A., ANDRIĆ, L.," The Construction and Ceramics Industry Waste Gypsum Valorization Possibilities", In: Proceedings of the IV Advanced Ceramics and Applications Conference, Atlantis Press, pp. 475-491, 2017.

[51] CONTRERAS, M., TEIXEIRA, S.R., SANTOS, G.T.A., et al., "Influence of the addition of phosphogypsum on some properties of ceramic tiles", Construction and Building Materials, v. 175, pp. 588-600, Jun. 2018. 
[52] SILVA, J. B., NASCIMENTO, R. M., MARTINELLI, A. E., et al., “Avaliação da Incorporação de Rejeitos de Gesso de Construção em Formulações de Massa Cerâmica", In: $17^{\circ}$ Congresso Brasileiro de Engenharia e Ciência dos Materiais, São Paulo, Nov. 2006.

[53] MELO, R. A. A., SILVA, D. G., "Estudo da viabilidade do uso do fosfogesso como matéria-prima na produção de materiais cerâmicos”, E-xacta, v. 6, n. 2, pp.13-31, Nov. 2013.

[54] DUARTE, C. N., FERNANDES, G., “Adição de Fosfogesso em Cerâmica Vermelha para Fabricação de Tijolos”, Revista Processos Químicos, v. 3 n. 6, pp. 55-60, Jan. 2009.

[55] RAKHILA, Y. A., MESTARI, S. A., ELMCHAOURI, A., "Elaboration and characterization of new ceramic material from clay and phosphogypsum”, Rasayan Journal of Chemistry, v. 11, n. 4, pp.1552-1563, Out.- Dez. 2018.

[56] LIMA, T. C., SOUZA, M. M., ALMEIDA, A. B., et al., "Aplicação de resíduos de gipsita em formulações de massas Cerâmicas", In: 22 ${ }^{\circ}$ CBECiMat - Congresso Brasileiro de Engenharia e Ciência dos Materiais, Natal, Nov. 2016.

[57] PEREIRA, C. L., MONTEIRO, F. M., "Estudo das propriedades tecnológicas de massas cerâmicas para revestimento com adição de resíduo de gesso da construção civil- parte 1", Abm Proceedings, v. 18, n.18, pp. 144-155, Out. 2018.

[58] SILVA, J.B., GONDIM, P.C.A., NASCIMENTO, R.M., et al., "Incorporation of Coating Gypsum Residues in the Formulation of Red Ceramic Mass", Materials Science Forum, v. 636-637, pp.1397-1403, Jan. 2010.

\section{ORCID}

Kelson de Almeida Silva de Almeida Roberto Arruda Lima Soares José Milton Elias Matos https://orcid.org/0000-0001-5540-3091

https://orcid.org/0000-0003-1892-7499

https://orcid.org/0000-0003-3476-399X 